\title{
DÜBLIN
}

Technological University Dublin

ARROW@TU Dublin

2003-09-01

\section{Moisture Re-distribution in Concrete Under Impermeable Coverings}

\author{
Niall Holmes \\ Technological University Dublin, niall.holmes@tudublin.ie
}

Follow this and additional works at: https://arrow.tudublin.ie/engschcivcon

Part of the Civil Engineering Commons

\section{Recommended Citation}

Holmes, N. and West, R., Moisture re-distribution in concrete under impermeable coverings, in Role of Concrete. International Congress on Celebrating Concrete: People and Practice, University of Dundee, Scotland, 2003

This Conference Paper is brought to you for free and open access by the School of Civil and Structural Engineering at ARROW@TU Dublin. It has been accepted for inclusion in Conference papers by an authorized administrator of ARROW@TU Dublin. For more information, please contact arrow.admin@tudublin.ie, aisling.coyne@tudublin.ie,gerard.connolly@tudublin.ie.

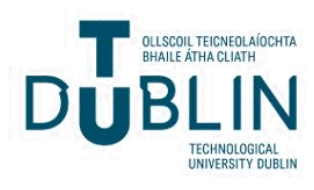




\begin{abstract}
It is normally considered safe to apply an impermeable floor covering to concrete surfaces when the surface relative humidity reaches $75 \%$ as determined by a surface hygrometer. However, over time, defects can appear on the covering such as blistering of vinyl and rising of tiles from the surface. One cause is the on-going diffusion of the residual moisture deep within the slab to the surface. The covering traps this residual moisture, thus preventing evaporation to the ambient air and gradually generates a vapour pressure underneath the covering, which can result in damage.

Here, experimental results on the long-term influence of an impermeable covering on the moisture condition in concrete in normal and forced drying conditions are presented. They show primarily that slabs in a forced drying environment result in a significant residue of moisture deep in the slab. As a result, a greater vapour pressure is generated under the covering compared with those drying at normal conditions. In order to predict this, a commercial finite element package (DIANA) has been used to model the influence of an impermeable covering on the subsequent re-distribution of the moisture through the depth of the concrete over time.
\end{abstract}

Keywords: Concrete Drying, Impermeable Coverings, Moisture Migration, Finite Element Modelling, Relative Humidity

Mr. Niall Holmes graduated with an Honours degree from Queen's University Belfast in 1998 and a Masters degree from Trinity College Dublin in 1999. He is currently a PhD student at Trinity College Dublin where he is researching finite element modelling of moisture migration in concrete during drying

Dr. Roger P. West is Head of the Civil Engineering Department at Trinity College Dublin. His research interests in concrete lie in durability, rheology and new materials. He is a former Vice-Chairman of the Council of the Irish Concrete Society and is currently the Irish Liaison Engineer for Eurocode 2. 


\section{INTRODUCTION}

Residual moisture in concrete floors is a major problem when waiting to apply impermeable coverings. If the covering is laid too early problems such as blistering of paint or vinyl may occur. The risk of this occurring leads to construction delays as the flooring contractor is forced to wait for the floor to dry to an acceptable level and results in a loss of revenue for the client as he/she waits to take procession of the facility. At present, floor coverings are applied to concrete slabs when the surface reaches a relative humidity $(\mathrm{RH})$ of $75 \%$, established using a surface hygrometer, as described by the British Standard [1]. However, this test gives no indication of the moisture condition deep in the slab. This is somewhat of concern as it is essentially the residual moisture condition deep in the slab that will determine how much damage, if any, will be caused to the covering over time. Work carried out at TCD [2], [3] has shown that significant moisture remains in the concrete after the surface has reached $75 \%$ $\mathrm{RH}$ on the surface, particularly if the slab is forced dried, using heaters and/or dehumidifiers.

If an impermeable covering is applied to a slab with excessive moisture below the surface, the covering seals in the moisture within the slab, thus acting as a vapour barrier to the ongoing vapour evaporation from the surface. This moisture will equilibrate through the depth over a relatively long-time (months or even years). An example of this is shown in Figure 1, there exists a greater residue of moisture deep in the slab which has been force dried than that drying in a natural environment, even though both sets of results are initially at $75 \%$ $\mathrm{RH}$ at the sealed surface. This condition sets up an internal humidity gradient, where, over time, the RH at the surface will increase due to the ongoing diffusion of the residual moisture to the surface which will be trapped under the impervious covering. Indeed, in Figure 1, the equilibrium relative humidity for the naturally dried slab and the forced dried slab has increased to almost 79 and $82 \% \mathrm{RH}$ at the surface respectively from an initial $75 \% \mathrm{RH}$. Gradually, due to this build-up of moisture under the covering, a vapour pressure will be created where the maximum extent of this pressure varies depending on the residual moisture at the time of sealing. This pressure will be sustained under the covering provided it remains perfectly impervious. Indeed, because of this, it is has become important to acquire some knowledge of the moisture condition deep in the concrete before any covering is applied, especially if accelerated drying is to be performed beforehand.

This project sets out to examine experimentally the effect of applying an impervious covering when a large residue of moisture remains deep in the concrete and presents results from experimental tests carried out on concrete slabs that monitor the changing RH at depth and at the surface using RH probes at various depths in the slab. The slabs were housed in two drying conditions; one in a laboratory with normal ambient temperatures and humidities and the other in a controlled 'room' with forced drying conditions such as elevated temperatures and reduced ambient humidities. When the surface reached 75\% RH (as indicated by the surface hygrometer) an impermeable covering was applied. The internal RH was continually monitored and the results show that the relative humidity redistributes through the thickness due to the humidity gradient set-up in the concrete at the time of covering. The measurement of the vapour pressure just under the covering was also measured using a pore pressure gauge and results show a steady increase in pressure over time. 


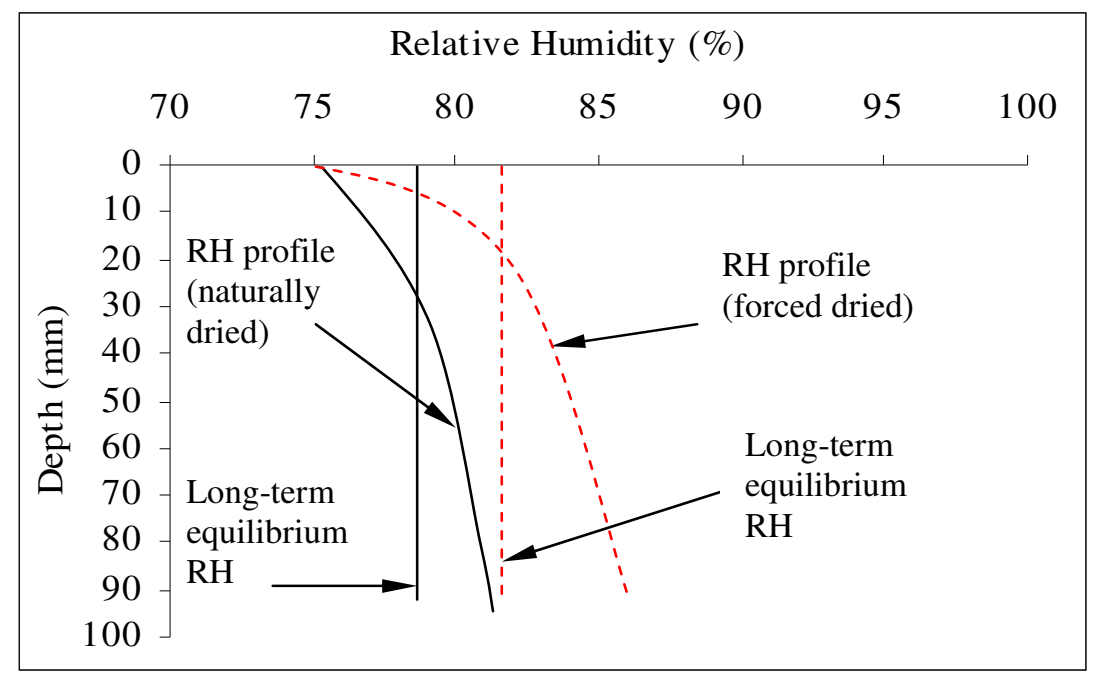

Figure 1 Typical short and long term RH profiles drying under natural and forced drying conditions in slabs sealed when the surface reaches $75 \%$ RH.

\section{EXPERIMENTAL WORK AND RESULTS}

To examine the effect of excess moisture in concrete floors on impervious coverings and the effect of accelerated drying on the moisture profiles, eight concrete slabs were poured, all $700 \times 700 \times 150 \mathrm{~mm}$ thick with $\mathrm{w} / \mathrm{c}$ ratios of $0.4,0.5$ and 0.6 . The concrete was made-up to achieve an average slump of $75 \mathrm{~mm}$ and a characteristic compressive strength of $35 \mathrm{~N} / \mathrm{mm}^{2}$. The slab with the w/c ratio of 0.4 was made with a standard dosage of a plasticiser admixture, to reach the required workability. The eight slabs were sealed on five sides, thus allowing drying through the top surface only and placed in two different environments; four in a laboratory with normal drying conditions, and the other four in a control room with elevated temperatures and reduced humidities achieved using a heater and dehumidifier. The average ambient conditions were approximately $14^{\circ} \mathrm{C}$ and $57 \% \mathrm{RH}$ for the laboratory and $38^{\circ} \mathrm{C}$ and $14 \% \mathrm{RH}$ for the control room. A number of holes were drilled in each to depths of $15,40,65$, 90, 115 and $135 \mathrm{~mm}$ using a masonry drill to measure the $\mathrm{RH}$ through the depth of the concrete using hand-held humidity probes. These probes were inserted into plastic tubes, which had been sealed into these drilled holes at the various depths. The plastic tubes were $72 \mathrm{~mm}$ long with an external diameter of $15 \mathrm{~mm}$ and extra lengths of the tubing were attached to one another to facilitate measurement of the $\mathrm{RH}$ at depths greater than $72 \mathrm{~mm}$. A plastic tube and humidity probe are shown in Figure 2.

With the arrangement of the rubber bung, as shown in Figure 2(a), an average RH reading was recorded approximately $5 \mathrm{~mm}$ above the base of the hole. The humidity probe (Figure 2(b)) was attached to a hand-held Relative Humidity Reader (RHR), which gives a digital output of the RH (Figure 2(c)). The surface moisture condition was also measured using both a Concrete Relative Humidity (CRH) and a Concrete Moisture Encounter (CME) [2,3]. The surface RH was measured using a conventional surface hygrometer [2], [3]. In addition, a number of Vapour Emission Tests (VET) were also performed. Figure 3 shows typical RH profiles in the slabs as they dried in the laboratory and the room for the $0.5 \mathrm{w} / \mathrm{c}$ ratio slabs. 


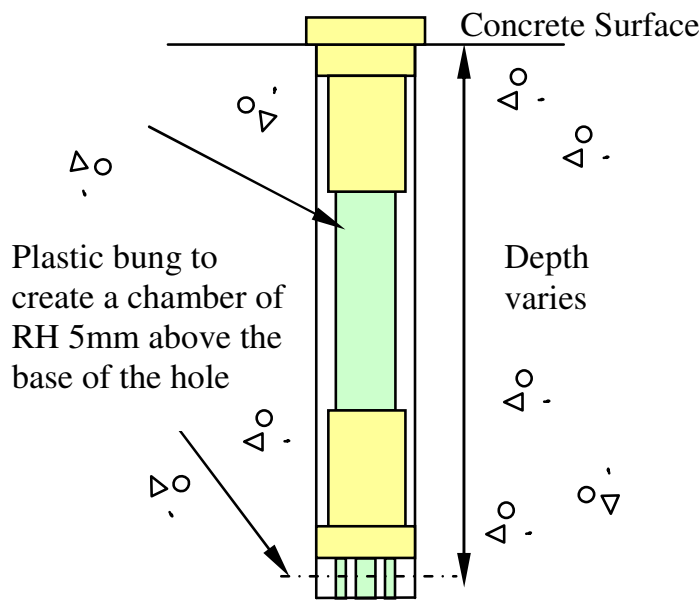

(a) Plastic tube

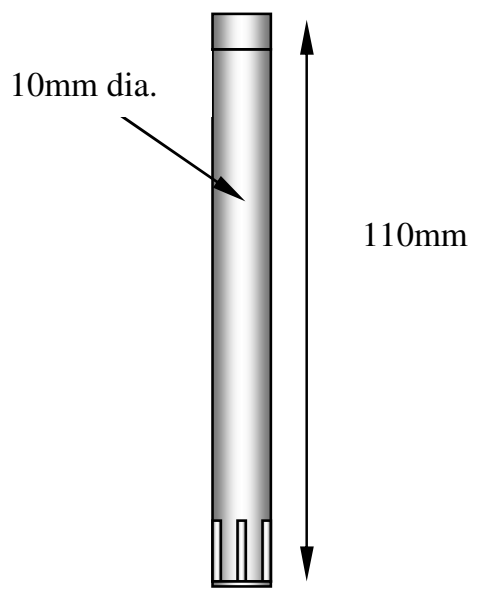

(b) Humidity Probe

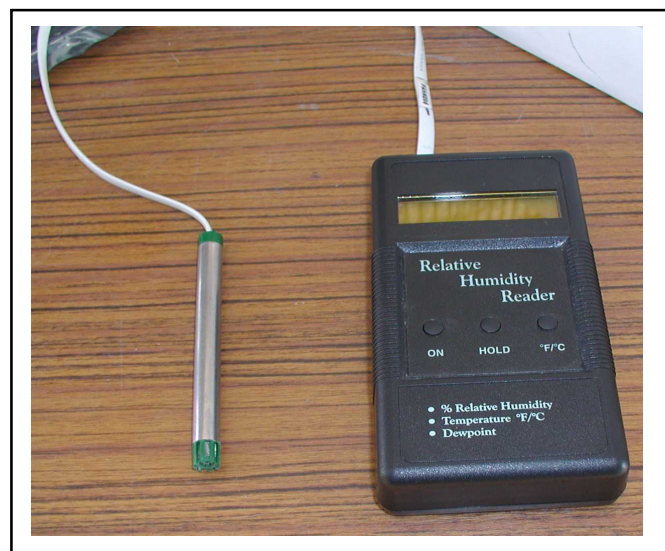

(c) Relative Humidity Reader (RHR)

Figure 2 Plastic tube, humidity probe and RHR used to monitor the RH

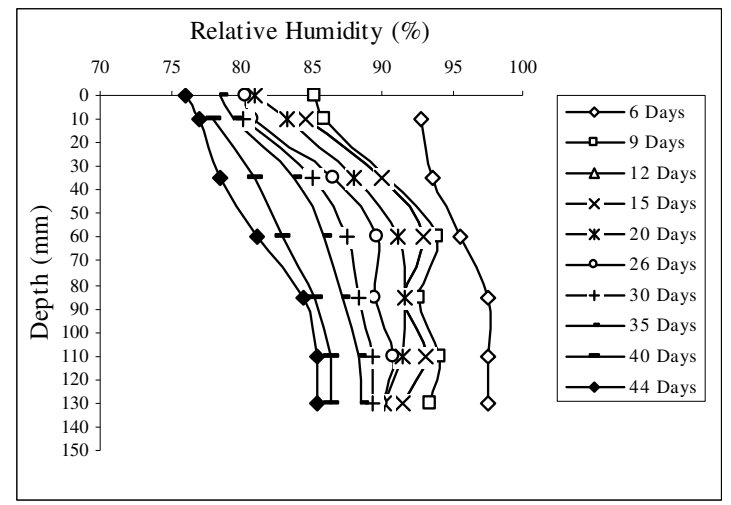

(a)

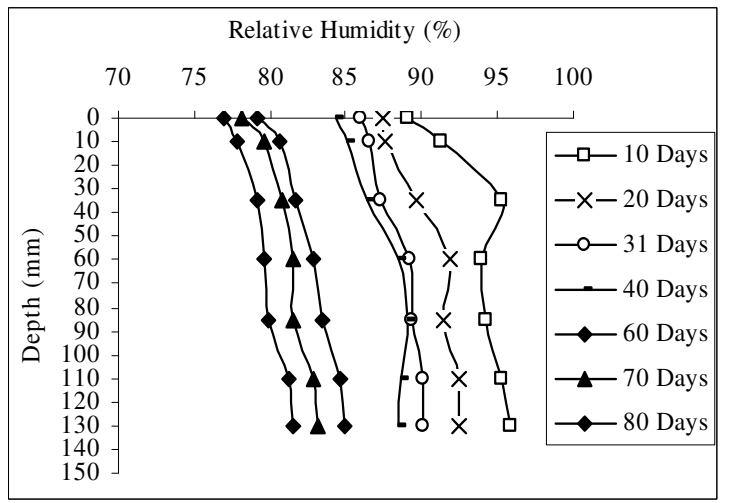

(b)

Figure 3 RH profiles for the $0.5 \mathrm{w} / \mathrm{c}$ ratio slab in (a) the room and (b) the laboratory. 
When the slabs reached $75 \% \mathrm{RH}$ on the surface (according to a surface hygrometer test), an impermeable vinyl floor covering was applied to the concrete, as shown in Figure 4. The RH at the various depths was monitored at frequent intervals after the covering was applied and Figure 5 shows the early age redistribution of the $\mathrm{RH}$ within the concrete after the covering was applied in the $0.5 \mathrm{w} / \mathrm{c}$ slab. Along with monitoring the $\mathrm{RH}$ profiles after application of the covering, the pressure development was monitored just underneath the covering, using pore pressure gauges (PDCR 81) attached to a Datascan unit that is set-up to read the pressure at hourly intervals. Before the analysis began, a calibration graph was set-up, which relates the output to the pressure. The set-up for this is shown in Figure 6, with the initial results from this pressure monitoring shown in Figure 7.

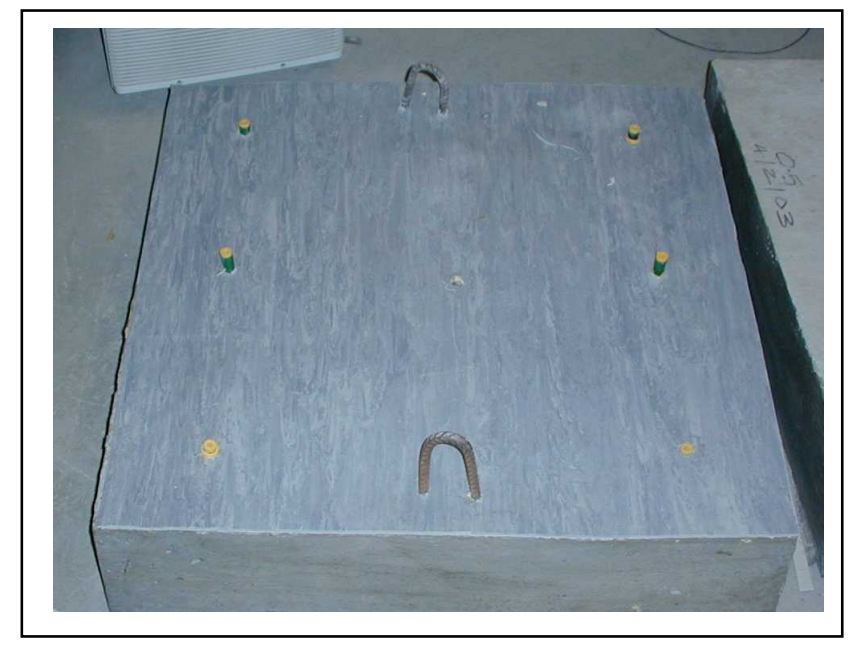

Figure 4 Covering applied to slabs in the room.

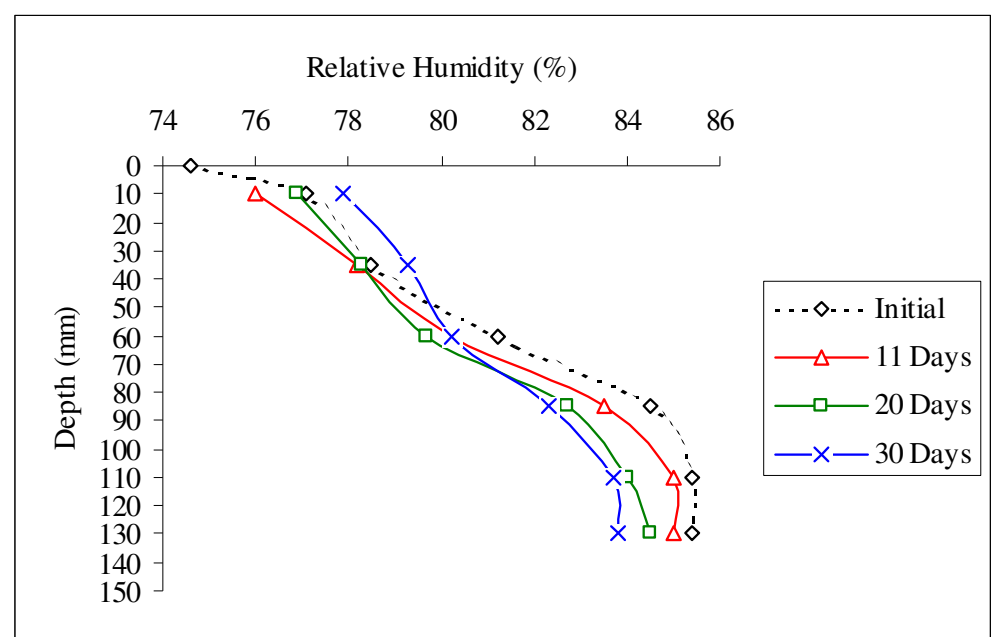

Figure 5 Re-distribution of the RH in the concrete after the covering was applied for the 0.5 -w/c slab 


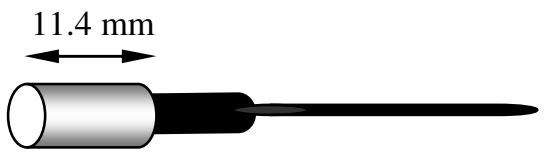

PDCR 81 Pore

Pressure gauge

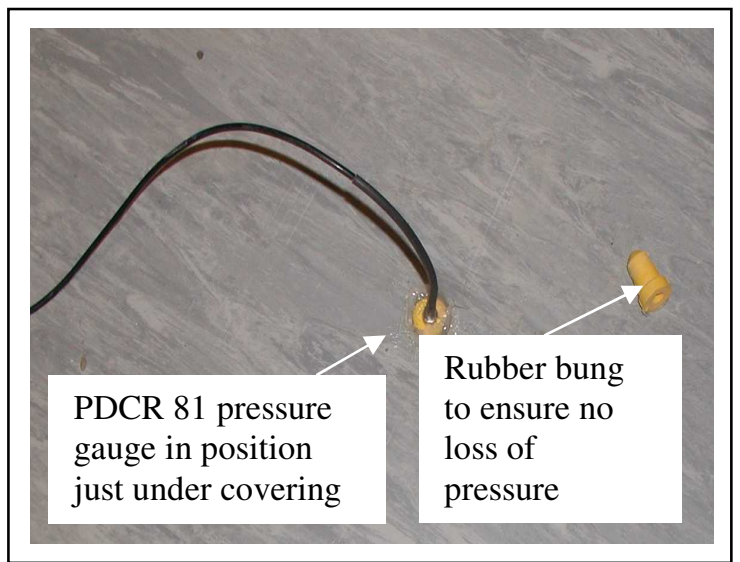

Pressure gauge in position

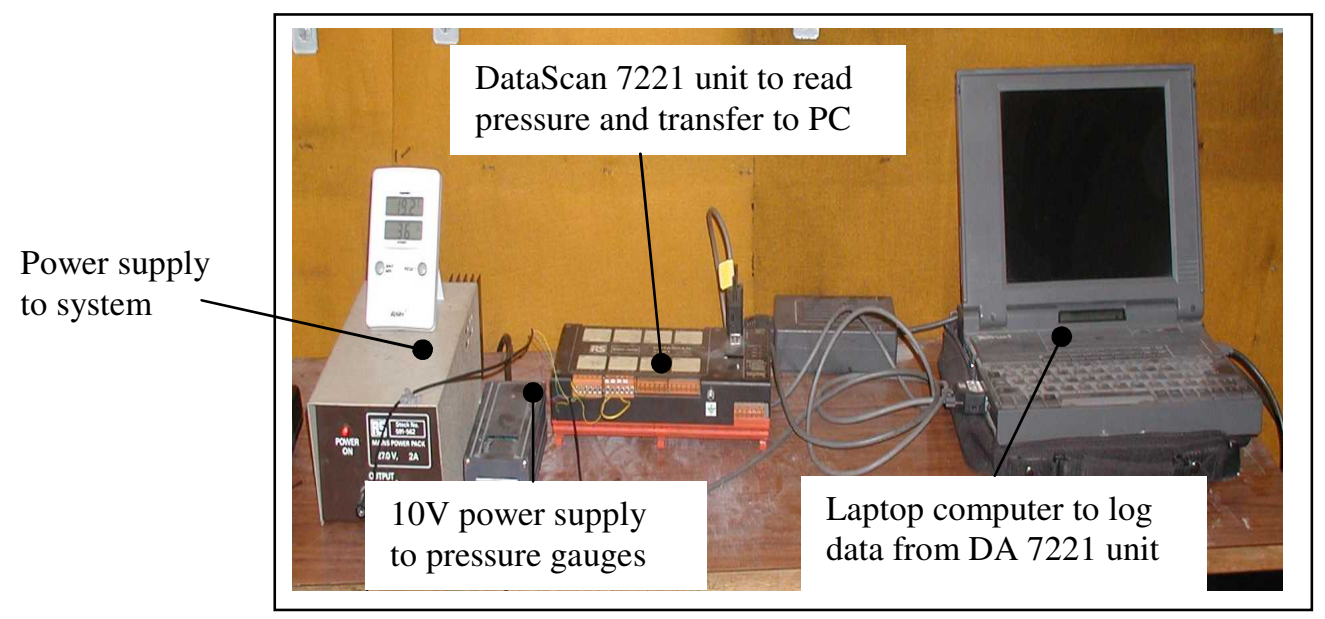

DataScan Unit

Figure 6 Set-up to monitor the build-up of vapour pressure under the coverings

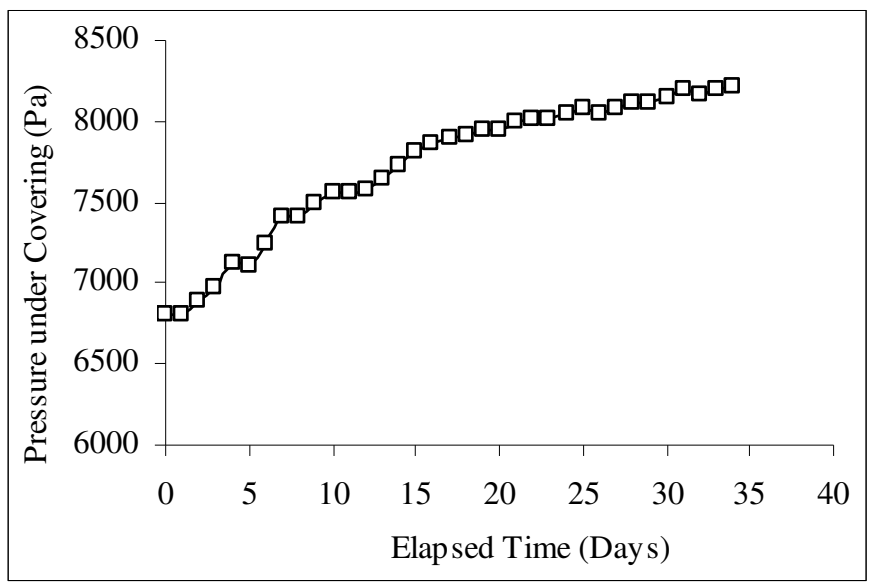

Figure 7 Initial vapour pressure profile $(\mathrm{w} / \mathrm{c}=0.5)$ for the concrete slabs in the controlled room. 


\section{FINITE ELEMENT ANALYSIS}

Using a commercial FE package (DIANA), a model has been set-up to predict the changing $\mathrm{RH}$ profiles during initial drying of the concrete and the subsequent redistribution of moisture in the concrete after the covering has been applied. Previous results from DIANA analyses [2] on the normal drying of concrete over time showed that this model gives very good agreement with experimental results based on non-linear diffusion coefficients in the concrete and evaporation rates from the surface, where the diffusion coefficient was given in terms of the internal pore $\mathrm{RH}$ and time dependent evaporation rates. The mesh used for the analysis consisted of 8-noded quadrilateral elements (CQ8HT) for diffusion within the concrete and 2noded linear boundary elements (B2HT) elements for the evaporation through the surface [2]. The four sides and the base of the slab were modelled as being fully insulated against moisture evaporation to mimic the experimental work and actual floor slabs on grade in domestic and commercial buildings, so that drying was taking place through one face only, such that only uni-axial moisture movement was taking place. The varying ambient temperatures and humidities were also included in the input. Figure 8 shows the results of the FE analysis for the drying stage using the input described above and, comparing these with the experimental results in Figure 3, suggests that the model gives a reasonably good prediction.

The second part of the FE analysis was to model the effect of the impermeable covering on the RH profiles over time. To do this, the existing model was altered to include an impermeable boundary at the surface representing the covering. This is easily done in DIANA where a 'no flow' boundary condition is specified at the surface to be maintained as impermeable over the course of the analysis. In addition, the initial RH through the depth of the concrete is also specified as the new initial profile when the surface reaches $75 \% \mathrm{RH}$, for example, like the RH profile in Figure 3 after 40 days for the slabs in the controlled room. Figure 9 shows the results from this analysis for the slabs in the controlled room only because, at the time of writing, only the room based slabs were covered. As shown, the results from the FE model give a good comparison with the experimental results in Figure 5.

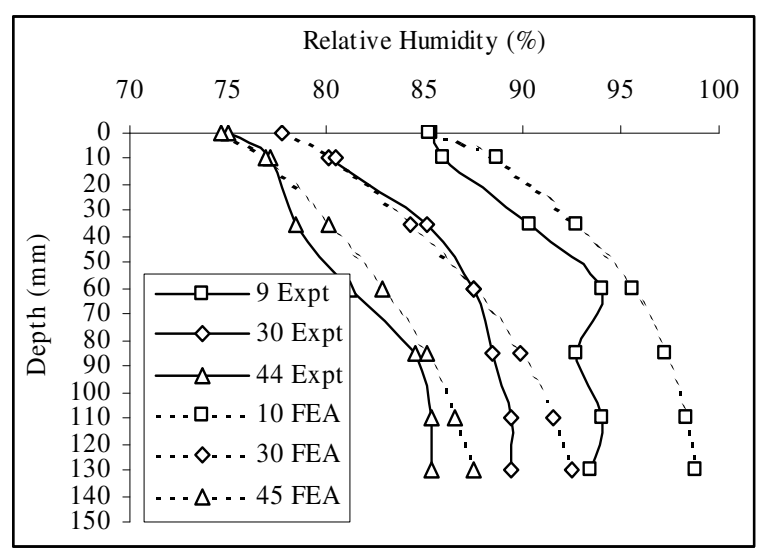

(a)

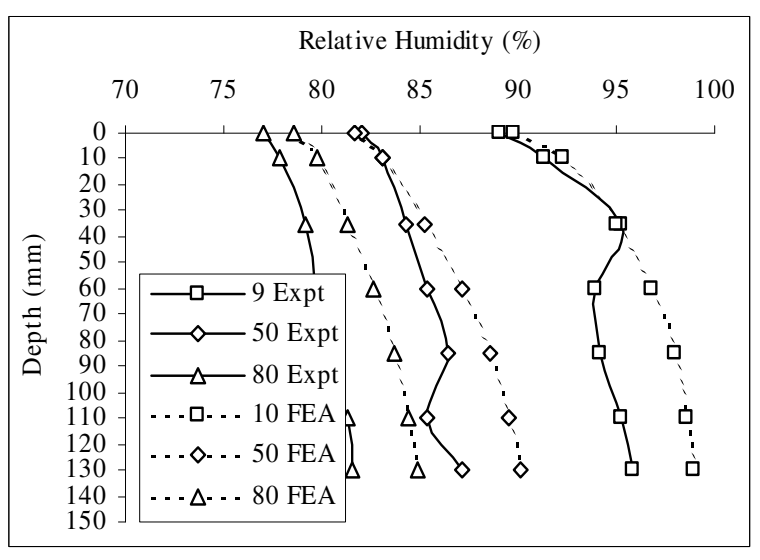

(b)

Figure 8 Finite element predictions for the $\mathrm{RH}$ profiles for the $0.5-\mathrm{w} / \mathrm{c}$ concrete slabs in the controlled room (a) and the laboratory (b) during normal drying. 


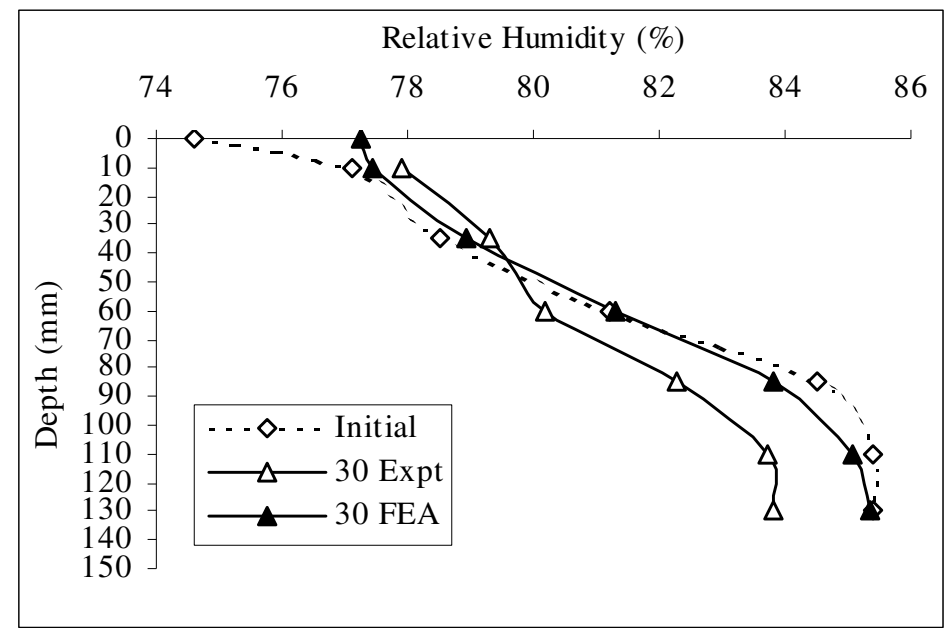

Figure 9 FE comparisons of the RH redistribution in the controlled room for the $0.5 \mathrm{w} / \mathrm{c}$ slab.

\section{DISCUSSION OF RESULTS}

It can be shown that the forced drying of concrete slabs before applying an impermeable membrane can indeed generate significant pressures underneath it over time, as shown in Figure 7. This pressure is derived from the on-going diffusion of moisture within the slab to the surface as it slowly reaches equilibrium within the slab. This may take some considerable time, but, when completed, the trapped moisture exerts a force under the covering, where, if it remains impervious, can result in serious damage to the floor covering. The results in Figure 7 are presented for the slabs in the controlled room only and, only when the laboratory based slabs are covered and the vapour pressure monitored, will a more complete picture of the effect of the residual moisture become apparent.

As well as the floor covering being affected by this increased vapour pressure, the adhesive may also be affected by the increasing moisture content or by the formation of salts, resulting in a significant loss in adhesion over time. Adhesives previously used for installation of floor coverings are now more water-sensitive due to the recent restrictions on the use of Volatile Organic Emission (VOX) products. Therefore, before a covering is applied to a concrete surface, the manufacturer will require that it reaches a 'safe' moisture condition before installation begins. Indeed, the ASTM standard [4] requires pull-off strengths between 20 and 145 psi $(138-883 \mathrm{kPa})$, depending on the type of apparatus used. Tests [5] on the pull-off strength showed that the adhesion of the covering varies for a dry and 'wet' floor for three different adhesives, epoxy, water-based and solvent-based for various levels of vapour emission rates established using a vapour emission test (VET) [2]. Most of the tests data indicates that the adhesive results decreased with higher water-emission rates.

Dissolved metal salts in the migrating water under the covering can form relatively large calcium / potassium silicates (in a typical alkali-silica reaction) and can cause 'swelling' under the covering. Also, the adhesion of floor coverings will be reduced when applied to a damp surface, or applied when moisture is still finding equilibrium inside the concrete. The 
ways round it involve either the choice of breathable-coatings, which reduce the vapour pressure by letting it escape gradually, or by surface damp-proof membranes that create a strong bond to a well prepared surface to dissuade the vapour from de-bonding the adhesive/covering from the surface. More sophisticated coverings gradually reduce the vapour pressure before finally excluding it and can be tested before the final floor finish is laid, to prove they are totally impervious.

The model shown here has produced consistent results in predicting the two-stages of the problem presented. The first stage presented is the normal drying of the concrete over time with varying ambient temperatures and humidities. The results shown from the model correlate to within $10 \%$ of the experimental results, using a non-linear diffusion equation varying with the internal $\mathrm{RH}$ and time varying evaporation rates. Following on from this analysis, the effect of applying an impermeable covering to the surface of the concrete when it reaches $75 \% \mathrm{RH}$ is also easily done by changing the boundary conditions at the surface (to represent a 'no flow' condition) and to input the initial RH through the depth of the concrete slab when the surface reaches $75 \%$ RH. From the results shown in Figure 8, the model does simulate reasonably well the increase in moisture under the covering due to the on-going diffusion of moisture lower down. Any significant differences in the results between the model and the experimental results may be due to the uptake of moisture by the adhesive or indeed the covering, which has not been included in the model.

Despite this, the results do give a prediction of the effect of applying such a covering to slabs with varying RH profiles through the depth of the slab. It has been suggested previously [3] that the use of a surface moisture test to determine the point to safely apply floor coverings is somewhat misleading as it gives no indication of the moisture condition deeper down. Therefore, as a result of this, the ASTM [6] has specified a method to determine the RH through the depth of concrete floor prior to application of any covering. The test sets out a detailed methodology using humidity probes, ultimately to minimize the risk of damages to concrete floors after application. This has been seen as a positive move as it highlights and recognizes the problem of below surface moisture.

\section{CONCLUSIONS}

This paper presents the results of an investigation into variations in $\mathrm{RH}$ profiles during drying of concrete slabs and the subsequent redistribution of the $\mathrm{RH}$ within the concrete after the application of an impermeable floor covering. The vapour pressure that develops slowly underneath the floor covering as the residual moisture in the concrete continues to diffuse towards the top of the slab is measured. This vapour pressure is more likely to cause damage to the covering, over time, if the slab has been forced dried. This results in high residues of moisture remaining in the concrete because of the drying regime and, hence, higher pressures under a sealed floor covering.. In addition, the FEM has been shown to be capable of predicting both the drying of concrete and the subsequent redistribution of moisture within the concrete after the covering is applied and shows reasonably good correlation when compared with experimental results. It is, therefore, obvious that the predictive numerical method demonstrated here, through the finite element method, could be a significant advantage in reducing if not eradicating this problem. 


\section{ACKNOWLEDGEMENTS}

The authors would like to acknowledge the help of Alan Rynhart and Sean Farrell of Tramex Ltd. for their technical assistance in the experimental work. The technical staff in the Civil Engineering laboratories at TCD also deserves a special mention for their help during the experimental stages of this work.

\section{REFERENCES}

1. BRITISH STANDARDS INSTITUTION, Code of Practice for Installation of Resilient Floor Coverings, BS 8203, 1996.

2. HOLMES, N and WEST, R.P., Moisture Migration in Concrete Slabs during Drying, Floors and Slabs, Proceedings of the International Congress-Challenges of Concrete Construction, University of Dundee, 2002, pp. 173-180.

3. WEST, R.P. and HOLMES N., Experimental Investigation of Moisture Migration in Concrete, Colloquium on Concrete Research in Ireland, NUI Galway, 2001, pp 39-44.

4. ASTM C 1315-95 Standard Specification for Liquid Membrane-Forming Compounds having Special Properties for Curing and Sealing Concrete, 1995

5. SUPRENANT, B.A. and MALISCH, W.R., Are your Floors Dry enough for Floor Coverings, Concrete Construction, pp. 671-677, August 1998.

6. ASTM F2170-02, Standard Test Method for Determining Relative Humidity in Concrete Floor Slabs Using in situ Probes, Approved July 2002. 